\title{
Empowering the Disadvantaged Students in Mathematics Education: Relevance of Social Justice, Equity and Mainstreaming
}

\author{
- Bed Prasad Dhakal \\ PhD Scholar, Graduate School of Education, TU
}

\begin{abstract}
Mathematical knowledge is indubitable in various sectors, but diversity in culture and tradition in society causes inequality, injustice and backwardness among the students learning mathematics. Study of cultural heritage, customs, behavior in mathematics education is the demand of post-modern paradigm. Efforts of self-organization and co-construction in the initiation of students and teachers through their active participation, interaction and mathematics classroom discourses could be instrumental towards the generation of mathematical knowledge in classroom - which can support to reduce the western domination in mathematics education; and societal negative mind-set about mathematics education will also be minimized in this way. Ethnomathematics, diversified mathematical strategies, culturally responsive mathematics classroom and enhancing equity in learning mathematics are the major dimensions that mathematics professionals need to exercise for the effective, reflective and contextualized teaching and learning of mathematics. This is a phenomenological study conducted among secondary level mathematics teachers. Using written interview and informal sharing of participants' experiences towards teaching and learning mathematics, three major themes were developed and discussed. This article primarily shows that there exists the intertwined relation among these themes; and it is essential to properly address these themes for more effective learning of mathematics in the context of Nepalese secondary level classrooms.
\end{abstract}

Keywords/terms: Contextualize, engagement, equity, justice, mainstreaming

\section{Introduction}

Multilingual and multicultural are the characteristics in present society almost throughout the country in Nepal. According to Central Bureau of Statistics (2014), sex ratio is accounted 94. Altogether 125 castes are 
identified with 123 different languages; and 10 different religions are reported throughout the nation including Hinduism, Buddhism, Islam, and others. The reflection of this scenario is seen in our school classrooms as well as the classroom of higher level. Classrooms in Nepal are multicultural and multilingual in general because students come to the school from various cultural and linguistic backgrounds. This context resonates with what Gates (as cited in Panthi and Belbase, 2017) expressed: "In many parts of the world, mathematics teachers are facing the challenges of teaching in multiethnic and multi-lingual classrooms containing immigrant, indigenous, migrant, and refugee children, and if research is to be useful it has to address and help us understand such challenges". Specially mathematics classroom is diverse in physical as well as socio-cultural dimension. Dhakal (2016) explains that the diverse background of students' and teachers' teaching culture has influenced mathematics education, its framework and overall philosophy of mathematics. Rickey (2017) emphasizes the characteristics of effective mathematics classroom with goal-oriented objectives, flexible grouping, safe environment, and organized materials and classroom. The agents of teaching and learning of mathematics are also important in our classroom. Thus, arrangement of mathematics classroom in a comfortable way encourages learning as well as instructing duty of mathematics teachers.

In grade 8,9 or 10 students spend 5 hours per week in studying mathematics in school. On period basis the mathematics subject is taught for 45 minutes in each class, each day as a compulsory subject up to secondary level in Nepal. In the context of Nepal, there is a curriculum development center that develops and designs curriculum that is implemented throughout the country. The curriculum is designed in line with natural science philosophy rather than human science. But very few are aware about the answer to questions like 'what is mathematics?', 'what is its implication and benefit in future?' At the same time, huge question of engagement in mathematics learning and co-construction will arise.

Till these days, without questioning we accept the imposed theories and practices without considering our richness of social and cultural diversity, geopolitical complexity, and local knowledge system (Panthi and Belbase, 2017) in our classroom. The dominant monolingual and mono-cultural western education system is so pervasive that it has severely affected teaching and learning mathematics in our country. Considering the explained 
variations in students' background, every mathematics teacher wants to be passionate about mathematics as well as about it teaching in general; they are committed and dedicated individuals with excellent communication and organizational skills. We generally believe that not all students like mathematics; in fact, many will find it positively boring. The key to being a good mathematics teacher is to find a way to make the subject interesting to even the most disinterested members of the class. The ideal mathematics teacher is one with a charismatic personality. A good candidate for a mathematics teaching position can breathe new life into the subject and assist those students who struggle with mathematics to gain confidence in their mathematicsl skills. Here is a statement by Jeremy Kilpatrick (Abreu and others, 2003) that points out: "We need to carry into our discussions of how different people coming from different cultures do different mathematics and different research". This is a key to committed and effective mathematics researcher as well as mathematics teachers in the mathematics classroom.

Issues of equity and social justice in mathematics teaching learning are important factors to be a teacher in the first place. Epistemological reflection (Wright, 2016) of secondary level mathematics teachers needs to be strengthened in present mathematics classroom as well as in surrounding culture and society. This paper argues that the situation of predomination of students mostly by mono-way of teachers would not be better towards learning mathematics in school level. That could not address the issues of social justice, equity and mainstreaming the disadvantaged mostly in mathematics learning in the context of Nepal. It recounts the experiences of mathematics teachers (ibid.) and the way forward in the development of their thinking and classroom practice that has implications for themselves and others involved in mathematics education.

\section{Objectives}

Socio-cultural structures of the students and their engagement opportunity in mathematics learning is the overall goal of this paper. On the basis of theoretical perspective and discussion with experienced mathematics teachers, the following are the specific objectives of this paper.

- To explore the theme of diversity in learning mathematics; 


\section{Empowering the Disadvantaged Students in Mathematics Education...}

- To formulate the theme of social justice and equity through and in mathematics; and

- To develop the mainstreaming theme by active engagement and interaction.

\section{Methodology}

In this phenomenological study, the major data gathering method involves primarily in-depth interviews with participants (Creswell, 2007) with the secondary level mathematics teachers. Seidman (2006) suggested that three serial in-depth phenomenological interviews with each of the research participants would be appropriate to collect phenomenological data. But this study, which is expository and based on the collection of experiences, only one formal in-depth interview was conducted with each of the participants named secondary level mathematics teachers who are currently in service.

Secondary level mathematics classrooms in Nepal are diversified in terms of the students' age, sex, caste/ethnicity, religion, culture, economic status and many more. The job of handling classroom strategies to address the diverse nature of students as well as differentiated physical facilities is complex for mathematics teachers. Thus, the teachers of mathematics having lived experiences were selected as the key informants for written interview. Here they are taken as first, second and third respondents. It was the purposive sampling that did not emphasze the size of respondents. Structured interview schedules were developed on the issues of diversity, equity and mainstreaming. Separated pages were provided to the respondents for response on each of the different questions.

Some clarifications were noted by the researcher himself. For more in-depth information on multiple dimensions of teaching and learning mathematics, personal open and informal interviews were conducted. Students' participation, engagement, interaction, game playing and many other activities were collected from teachers' side only. The experience of teaching profession, students' interaction, engagement, and their performance in mathematics on the basis of culture and social backgrounds of students were thoroughly discussed during the collection of information. After my request and sharing the research objectives, the respondents came to consensus with good rapport and thus were ready to share their experiences and the incidents occurred in their professional career. Thematic 
discussions on three different global themes called diversity, equity and mainstreaming in mathematics learning are discussed on the basis of experiences, practices and belifs of the respondents.

\section{Constraints}

As common, the result verification issues due to the theme development from teachers' side is taken as major constraint of this study. Although various social theories like social-justice theory, co-construction theory, engagement theory, mainstreaming theory etc were connected in this study, they become expository, complementary and guiding but cannot be prescribe. Interconnected nature of phenomenological study may take the relevance and authenticity issue in this research. Diversity in terms of physical handicap and disabilities were not consider here. Social justice or its consequence termed equity among the students was limited only in mathematics teaching and learning practices, strategies that were experienced by teachers was considered here. Opportunity in lead role in terms of playing mathematical game, solving mathematical problem with fun and presentation through social aspect but not economic was due mainstreaming discussion among the mathematics teachers.

\section{Discussion and theme generation}

Theoretical perspective to address multilingual, multicultural, multi-capacity and overall diversity of students in secondary level mathematics education is connected to the experiences and practices being utilizing by secondary level mathematics teachers. Social justice in the aspect of equity enhanced by mathematics teaching and learning as first coined by Nancy Fraser (Deqiang and Xiaonan, 2015) is equally important to address the contemporary inequality issue in front of mathematics curriculum developers and decision makers. The active and regular engagement of students is required in each type of mathematics problem solving, games and puzzles, interactions, discourses and presentations (Kearsleym and Shneiderman, 1998) that use the local as well as common technology in teaching and learning mathematics. Doing so, the mathematical knowledge of our diversified students are benefitted and the practice of utilization of cultural context in mathematics classroom comes into reality. Emile Durkheim, the structural functionalist, has the strong voice towards mainstreaming (Hudson, 1978) 
students in learning with the support of Jean Piaget's co-construction, aroused by the collaboration between teachers and students.

On the foundation of above theoretical discussion, the information collected from field notes, in-depth interview with mathematics teacher, and informal interaction with them made through regular follow up and friendship environment between researcher and respondents, three main themes are developed below. Since diversity, equity and mainstreaming are the interconnected dimensions in learning mathematics, they cannot be discussed separately; so these themes are described accordingly in the next sub-headings.

\section{Diversity in mathematics learning}

As our society is diverse in terms of being multi-cultural and multi-lingual, mathematics classroom is obviously seen diverse. Cultural diversity includes the various social structures, belief systems, and strategies. The main theme explored here includes the different cultures that we encounter in mathematics classrooms and how these cultural differences influence mathematics learning. Altogether 123 different languages are spoken in our country; and, teachers' side, our students have about ten different religious backgrounds. There is a big risk to retain them in classroom and develop social harmony by preventing their early exit (dropout) from school. One of the respondents told that not only the culture and language, there is the vast diversity in students in terms of their economic background and consequently their knowledge and ability level. Even the homeless students and those work in hotels and private houses are found in schools, so they have little time to do mathematics as we expect generally. The same respondent also added that he never got the issue of age gap and sex differences among students did not matter much in teaching; but differences were noticed sharply among them as regards skill and encouragement. Due to the socio-cultural practices, there is a high rate of irregularity of students, which is not just limited to a particular student. Almost all students remain absent in school on one day or the other, as said by the second respondent. According to Bourdieu's (Edgerton and Roberts, 2014) idea of cultural capital, students are self-categorized as first bench-sitters having the lead role in mathematical games and puzzles who are from middle class families and have a bit higher level of cognition. On the other hand, the backbenchers are often not willing to participate in classroom engagement, and 
get less opportunity to get benefit in learning, as experienced in the mathematics classroom of the second respondent. Such a discriminatory practice needs to be minimized by introducing culture-specific games, knowledge, materials and other meanings in real classroom practice according to him.

Responses of the first two respondents, on one hand, agree that students in a large number show dissatisfaction (Wright, 2016) who characterize school mathematics as being boring, irrelevant and passive - ignoring individual needs and teaching rules without any practical rationale because it is too formal, monolingual and rigid. On the other hand, somehow successful learners also want to alienate from mathematics due to the fear of being identified as passive receivers of mathematical knowledge. Like Banks (as cited in Acharya, 2015), all three respondent teachers emphasized the need for content integration in curriculum, communication of it to the students with diverse ethnicity. Similarly, they also pointed out the need to prioritize their responses by reducing biases, practicing equity pedagogy, empowering mathematics classroom culture and social culture, etc. (ibid.). These would be the ways of addressing socio-cultural diversity of students in mathematics classroom. In the same direction, the problem would be addressed by encouraging the low achievers in mathematical knowledge with the support of group work, discourses and interactions.

\section{Social justice in terms of equity in mathematics}

Positive discrimination in favour of the disadvantaged, backwarded and the excluded students of mathematics is the process of establishing equity in mathematics education. Establishing equity in mathematics learning among the secondary level students is not a separate and isolated wing from the issue of addressing diversity and mainstreaming the disadvantaged. It is intertwined among all the efforts laid down for effective mathematics learning, eliminating social conflict cum maintaining social harmony, and ultimate prosperity of nation through the contribution of mathematics teaching-learning. Losing hope, the third respondent remarks: "Equality does not work among the students having varied characters in our mathematics classroom in the course of teaching-learning". The need for equity in mathematics education should be emphasized (Fatma and others, 2011) as suggested by the National Council of Teachers of Mathematics in the US. The council argues that the achievement of equity in the mathematics 
classroom should not be a tool to increase the workforce and support economy. High expectations, worthwhile opportunities, accommodation of differences and support for all students are necessary to maintain the equity in every mathematics classroom. The first instructor mentions that class size is one of the factors hindering equity in mathematics learning due to the defined time frame given by the national curriculum. The third respondent expresses the thought that schools' culture was not favorable for culturally diverse students. So, there is lack of equity in Nepalese classrooms (Acharya, 2015). According to Bourdieu (Edgerton and Roberts, 2014), the unequal power relations exist in rooted form in our society and the prime function of schooling has been to reproduce the current social order and to maintain unequal power relations rather than doing anything to reverse them. Thus, the claim of cultural capital by gifted or merited students is safely handled and valued by schools even by mathematics teachers. Likewise, the students from middle families acquire higher level of cultural capital than those from working class families placing them at an advantage before they arrive at school. Here, in his (first respondent's) school, most of the students are from working class family and some are without family. Thus, not only mathematics but also overall academic performance is so weak. Interaction and engagement supports them whereas a few students of Newar community want to link the cultural signs to the mathematics learning that support to maintain the social justice in mathematics classroom and its learning.

New research is our demand as questioned by the second respondent, on the question like: How to gain equity in our mathematics classroom and generate knowledge accordingly? The answer of this question demands the changes in existing epistemologies in mathematics education. Likewise, the students' self-organization is another means to develop their own agency so that they are encouraged towards engaged and critical learning of mathematics. Classroom discourses will play a more effective role to enhance the students' ability and attainment, as suggested by the second respondent for the opportunity of equity treatment in mathematics teaching and learning.

\section{Mainstreaming of the disadvantaged students in mathematics learning}

Disengaging the students and damn care about their cultural perspective would be the cause, according to the first respondent. The third respondent also has similar statements and experiences in his school. He added that social class of the students playy the crucial role in participation, interaction 
in mathematical activities; and this situation inevitably leads to the perpetuation of social inequities among them. Evidence suggests that teaching mathematics to the diversified group of students through more open-ended, collaborative, problem-solving approaches leads to more equitable outcomes and promotes greater participation among both boys and girls (Boaler, n.d). Thus, it is better to minimize the conventional approaches to teaching and learning mathematics at secondary level in our schools.

There is the consensus among my participant teachers that a more relevant and engaging (Wright, 2016) mathematics curriculum is needed with greater emphasis on conceptual understanding and problem-solving in mathematics education. In the response of the third respondent, mathematics learners should reflect through mathematics by engaging in meaningful mathematical inquiries in which they pose their own query and take their decision at the time of co-construction, interaction and communication with peers, teachers and outsiders as well. Students' reflection with mathematics are seen during their presence in the social, cultural, economic and political affairs. He (third respondent) still focuses on student's volunteer engagement rather than forceful. Empowering his students in mathematics learning is possible only if the students use mathematics to investigate and challenge injustices and inequities relating to their own lives and wider society. In the 10 years of his experience in mathematics teaching, he focused on drawing learners' reallife experiences in order to emphasize the cultural relevance of mathematics to promote mathematical inquiries that enable students to enhance the understanding of their own social, cultural, political, and economic situation.

Paulo Freire's best-known 1968 work, The Pedagogy of the Oppressed (Mahmoudi and others, 2014) became a milestone document to address the students who are backwarded and disadvantaged in academic performances. Frankenstein defined (Fatma and others, 2011) critical mathematics literacy as "understanding mathematics in a way that will enable you to use that knowledge to cut through the 'taken-for granted' assumptions about how our society is structured and to act from more informed choices about those structures and processes". Positive discrimination to the students in mathematics learning activities and knowledge generation in students have been practiced as voiced by third respondent. In the opinion of the third respondent, providing extra space for learning such as books, copy, mathematical instruments and additional free classes to the disadvantaged 
students have been practiced in his school not only in mathematics class but also in all subjects. All academicians, specially mathematics professionals claim that mathematics helps to understand relations of power, resource inequalities between different social groups and explicit discrimination (Fatma and others, 2011). It deepens the students' understanding of society and prepares them to be critical, active participants of democracy; but these professionals remain silent in concretizing this claim, as pointed out by first respondent. In the line of first respondent, the second respondent also experienced that the voices of bringing the disadvantaged students to the front seat are heard everywhere but he himself is afraid of implementing this idea in most of the mathematical engagements and activities. They are weak in subject matter, they have lacks in basic things like books, bags, geometry boxes, even the regular uniform. Such lacks among the students in government schools is shameful as added by the second respondent. But there is not so much lacking like in second respondent's school, as told by the third respondent in his school. He says, "I have some back sitters and weak students in mathematics. I have been trying by letting them as a leader in many discourses, puzzles, mathematics fun, and raising their cultural positive incidents to bring them to the forefront in mathematics learning." We heard Piaget's theory of co-construction and making mathematical meaning through the interaction between students and teachers and between students only as summarized by all three participant teachers.

\section{Conclusion}

Diversity is in our society and so in classroom. To develop and maintain social harmony through mathematics classroom of secondary level in Nepal is one of the most challenging issues not only to the policy makers but also to the academicians, mathematics teachers, society and even to the students. This study has attempted to explore the issues of diversity, maintaining equity and mainstreaming in mathematics learning. Teaching pedagogy should be culturally contextualized by using "democratic teaching" metaphor (Luitel and Taylor, 2007) that is better to get harmony in diversified culture and social structure in our context. There is a lack of self awareness and sufficient research and practical works on cultural-specific, justice based pedagogy in mathematics learning. Some research works have been undertaken in the area of culture, justice, language based mathematics teaching and learning. Empowering, liberating, emancipating, enlightening 
and encouraging (Fatma and others, 2011) the students through critical pedagogy will help to develop our local mathematical knowledge. Due to the difference of students' mother tongue and formal (Nepali and English) medium of instruction in mathematics classroom, the students are found discriminated in learning mathematics. This discrimination ultimately creates barriers towards the route of making high expectations from students in mathematics. Many alienations would be the cause of not addressing different cultural backgrounds of students. Mathematics classroom, teachers, politics and other factors are now ready to develop a social harmony, cultural enhancement and equity through the culturally contextualized curriculum. Individual insight and capability of students are promoted through the cultural practices in overall mathematical activities in the classroom. The curriculum that is flexible, subjective, culture-specific, interactive and timespace specific is taken as culturally contextualized curriculum (Hilbert, 2010). This idea is in consonance with the results of discussion among participant teachers, as found in the literature referred in this study.

Most of the Nepalese mathematics classrooms are rigid, one sided, and follow the traditional teacher dominated approach to teaching-learning. Socially constructed, student centered, interactive pedagogy is the demand of new era, so that the student can compete and face the mathematical problems arising in their workplaces and society on their own. 'Taken-for granted' (Fatma and others, 2011) knowledge in mathematics kills the creativity of students and falls within the trap of discrimination. To break the tradition of imposed learning in classroom (by imparting the concrete, formal and closed contents), our mathematics classrooms need to become more critical, interactive, inclusive and continuous (Kaiser, 2008). Focus group discussion, discourses, locally available teaching learning materials have been used in our secondary level mathematics classrooms. On one hand, only the nominal critical pedagogical practices are possible in our mathematics classroom due to the goal (exam) oriented curriculum system. On the other hand, the size of students' population in a classroom and the materials and instruments found in the classroom setting do not match for effective pedagogy in mathematics.

This study developed a conceptualization of teaching and learning mathematics for social justice, equity and mainstreaming that challenge the tradition of 'status quo', disengagement and disempowerment from the perspective of the backwarded and disadvantaged students in mathematics 
education. It will help to draw on Freire's (Skovsmose, 2011) notion of critical education which advocates the release of learners and the development of critical citizens. It is assumed that mathematics education can and should play a vital role in addressing many struggles faced by our society including inequality, loss of human rights, unsustainable economic growth and overall social injustice.

This process allows teachers to develop a more profound and critical understanding of their own practice and how this relates to existing practice across different schools. The summary of discussion can lead towards greater awareness on the structural causes of inequity and injustice in mathematics education.

\section{References}

Abreu, Guida de; and Gorgorio, Nuria. (2003). Diversity in mathematics education: Social and cultural challenges. CERME3, Bellaria, Italy.

Acharya, Bed Raj. (2015). Relevance of primary level mathematics education in Nepal: A cultural perspective (Unpublished Doctoral Dissertation). Tribhuvan University, Kathmandu, Nepal.

Boaler, Jo. (n.d.). Promoting 'relational equity' through a mathematics approach focused upon social justice. University of Sussex. Retrieved from: https://www.unige.ch/math/EnsMath/Rome2008/WG3/Papers/ BOALER.pdf.

Central Bureau of Statistics. (2014). The population monograph. CBS, Nepal.

Creswell, John W. (2007). Qualitative inquiry and research design (2nd ed.). New Delhi: Sage publication.

Deqiang, Xu; and Xiaonan, Hong. (2015). Critical reflection on Nancy Fraser's theory of justice. Cross-Cultural Communication, Vol. 11(9), pp. 43-47. DOI:10.3968/7519.

Dhakal, Durga Prasad. (2016). Philosophy of mathematics and its relevance in maths classroom. Kathmandu University, Nepal.

Edgerton, Jason D.; and Roberts, Lance W. (2014). Cultural capital of habitus? Bourdieu and beyond in the explanation of enduring 
Empowering the Disadvantaged Students in Mathematics Education...

educational inequality. Retrieved from https://doi.org/10.1177/ 1477878514530231 .

Fatma, Aslan Tutak; Elizabeth, Bondy; Thomasenia, L. Adams. (2011). Critical pedagogy for critical mathematics education; International Journal of Mathematical Education in Science and Technology, vol 42. doi: 10.1080/0020739X.2010.510221.

Hilbert, Paul. (2010). "The gospel in human contexts: Changing perceptions of contextualization," in Mission shift, edited by Hesselgrave, David; and Stetzer, Ed (Nashville, TN: Broadman and Holman, 2010), p. 8499.

Hudson, Joe. (1978). Structural functional theory: Social work practice and education. Journal of Sociology and Social Welfare, vol. 5(4/4). Retrieved from https://scholarworks.wmich.edu/jssw/vol5/iss4/4.

Kaiser, Gabriele. (2008). Meaning in mathematics education: Reflections from various perspectives. Retrieved from https://www.unige.ch/math/ EnsMath/Rome2008/ALL/Papers/KAIS.pdf.

Kearsleym, Greg; and Shneiderman, Ben. (1998). Engagement theory: A framework for technology-based teaching and learning. Educational Technology. Retrieved from http:// home.sprynet.com/ gkearsley/ engage.html.

Luitel, Bal Chandra; and Taylor, Peter Charles. (2007). The shanai, the pseudosphere and other imaginings: Envisioning culturally contextualised mathematics education. Cultural Studies of Science Education 2(3), pp. 621-638.

Mahmoudi, Ayoub; Khoshnood, Ali; and Babaei, Abdolrazagh. (2014). Paulo Freire and the role of critical pedagogy Vol.5 (14), Retrieved from https://www.iiste.org/Journals/index.php/JEP/article/viewFile/ 12993/13309.

Panthi, Ram Krishna; and Belbase, Shasidhar. (2017). Teaching and learning issues in mathematics in the context of Nepal. Retrieved from https://files.eric.ed.gov/fulltext/ED573754.pdf.

Rickey, Susan. (2017). Characteristics of an effective mathematics classroom. Retrieved from https://classroom.synonym.com/characteristics -effective- 
Empowering the Disadvantaged Students in Mathematics Education...

mathematics-classroom-18577.html.

Seidman, Irving. (2006). Interviewing as qualitative research. 1234 Amsterdam Avenue, New York, NY 10027: Teachers College Press.

Skovsmose, Ole. (2011). An invitation to critical mathematics education. Rotterdam/Boston/Taipei: Sense Publishers.

Wright, Pete. (2016). Social justice in the mathematics classroom. London Review of Education, DOI: 10.18546/LRE.14.2.07, Vol. 14(2), UCL Institute of Education, University College London. 